\title{
An alternative measure of Standard of Living: The Body Mass Index in Colombia ${ }^{1}$
}

\author{
Luis Fernando Gamboa \\ Nohora Forero Ramirez **
}

\begin{abstract}
This paper assesses the standard of living using health-related outcomes instead of income-based measures. We use the Body Mass Index (BMI) as a categorical variable to take into account how far people are from a normal range associated to a desirable quality of life. This is a proxy of the Standard of Living Index for the Colombian case. An OrderedProbitModel is used to determine the probability of being within that normal range or not, with two different specifications: the normative one that takes into account the traditional categories in which the BMI is ranked,and the relative one, in which the distribution of the sample is incorporated. We found that education and a constructed index of living conditions have a significant effect on the dependent variable and that there are non-linear effects. We also found that people with walking difficulties and adults have less probability of having a normal BMI.
\end{abstract}

Keywords: Standard of Living, Body Mass Index, Wellbeing, Overweight.

JEL: C35, D63, I19

\footnotetext{
1 We want to thank DHS-MacroInternational and Profamilia, for access to data, and Ana Vega (from Profamilia) for her kind help. We also acknowledge the comments by the participants to seminaries at Facultad de Economía- Universidad del Rosario, CID-Universidad Nacional (Bogotá), Latin American Studies Association, Rio de Janeiro 2009, and Simposio Nacional de Microeconomía (Universidad Externado de Colombia). Finally, we would also like to thank the comments and suggestions of three anonymous referees.

* Universidad del Rosario (Bogotá-Colombia). Contact details: Phone (571)-2970200 ext 8013 , e-mail: luis.gamboa@urosario.edu.co

** Universidad del Rosario (Bogotá-Colombia). E-mail: forero.nohora@urosario.edu.co
}

Revista Econômica, Niterói, v 13, n 2, p. 77-99, dezembro 2011 


\section{Introduction}

Traditional views on standard of living measures have been focused on expenditure,per capita Gross Domestic Product, wages, income,income distribution, and poverty. Nevertheless, the literature has recognized that sometimes such measures do not allow realcomparisons among countries, because of the difficulties that arise when using monetary variables (i.e. purchasing power parity, preferences, and traditions) and their dependence on income distribution. However, according toother theoretical approaches such as Sen $(1987,1987 b)$, the standard of living is not the same as opulence, even though it is influenced by it.Therefore,the study of the standard of living requires combining several dimensions of the human life.In fact, having money allows people to afford many things but this condition does not guarantee an increase in welfare, in happiness or in health for everyone. Traditional approaches used to consider the per capita income -due to its facility to obtain- under the assumption that income is the source of the satisfaction of needs. In order to undertake this drawback, it has been constructed a serie of composed indicators of standard of living by combining several dimensions such as the Human Development Index (HDI). It is clear that there is a trade-off between simplicity and completeness in any measure of standard of living. Single indexes are easy to interpret and use, but do not recognize other aspects; meanwhile, composed indexes provide a balance of distinct dimensions though they are not always free of critics because of the inclusion or exclusion of some variables.

As Sen (1987) states, there are different ways to approachthe concept of standard of living. "...you could be well off, without being well, you could be well without being able to lead the life you wanted, you can have this life without being happy and so on". From his point of view, the standard of living includes the capabilities and functionings that the individual can do. A functioning is an achievement, whereas capability is the ability to achieve. Thus, functionings are better for evaluating living conditions because they are related to a more comprehensive informational basis of people. The standard of living includes what people can be or do with their goods and it lets us understand the link among goods and living conditions. ${ }^{2}$ Therefore,

2 For more details about standard of Living, see Sen (1987). 
the standard of living could be measured by using alternative indicators of variables that reflect people's real situation. As a result, non-traditional health indexes could serve as a proxy of the type of life that people have. Health conditions could be related to wealth, but this is neither deterministic nor uni-directional. The causes of having good health include having access to education, healthy food, enough money to afford goods and services, genetic conditions and some random factors. It is an outcome of the type of life that people have.

Our purpose is to assess whether the BMI can be associated to an alternative measure of standard of living.The BMI is traditionally defined as weight in kilograms over squared height in meters. But in contrast to public health literature, we are interested in assessing how far away people are from the normal BMI range and to explain what determines that situation. The way to do it is by evaluating the relation between the BMI and Socioeconomic variables such as: educational level, socioeconomic stratification, or wealth index, among others. In particular, although there are distinct causes for low or high values in the BMI, it is clear that both are associated to worse health and physical living conditions. As a result, we are interested in evaluating what are the determinants of the probability of being in a normal range or being out of it. As a consequence of the data availability and unobserved factors, we cannot test a causal effect in our model but we could provide an estimation of the determinants of being in ranges far from the normal body mass index. We recognize that the use of this measure could be limited because the set of factors that can affect it and their complexities. Other measures such as the height for age z-scores (HAZ) in children could also be used,but the sample size for children is very small to extract robust conclusions.

The empirical strategy used in the document confirms that there are nonlinear relationships between age, socioeconomic status and the BMI. In fact, the main findings indicate that women and men exhibit different patterns. The evidence also suggests that it is necessary to deep into the design in public policies focused on school-food programs for carrying the children to the normal range.

The document is subdivided as follows. The second section describes the meaning and implications of the BMI. Subsequently, the third section shows the data and the model, and finally the last one examines some policy highlights. 


\section{Background}

Traditional literature on standard of living measures rests on multidimensional indexes. We find two types of measures. On the one hand, there are those in which the standard of living is proxiedby socioeconomic status (SES, hereafter); among them we have the HDI, which basically includes income, life expectancy, and education, and the Living Conditions Index (LCI) which includes information from self-perception of the household's living conditions, physical and human capital variables and demographic aspects(See Gamboa and Guerra,2006).

On the other hand, we find measures that associate standard of living with non-monetary dimensions that represent other spheres of human life such as: height, weight, BMI, literacy rates, life expectancy, morbidity, access to drinking waterand illness. This branch goes beyond the economic sphere. Among these dimensions, there are several studiesthat link anthropometric conditions with the standard of living (Steckel, 1985), Fogel, 1989, and Meisel and Vega, 2006).Steckel (1985) and Fogel (1989) associate standard of living with the stature of the people. According to Steckel (1985), stature is an appropriate indicator of health status (indirectly) that reflects not only genetics but also environmental conditions and it can give information about history of net nutrition. Besides, it is highly correlated with production -a more common measure of living standard- and it allows us to analyze the relation between nutrition and productivity since height depends on factor such as diet, medical care, and exercise during childhood, among others, which may be influenced by socioeconomic factors.

Some studies have found that in developing countries, the BMI for adults is positively related with other measures of development as income or expenditure, and specifically, there is evidence in Ghana that shows that the BMI can be used as an indicator of standard of living (Nubéet al, 1998). Nubéet al (1998) found that the direct relationship between BMI and the characteristics of households analyzed makes it possible to expect that differences in standard of living may be reflected on the BMI.

Although height is also positively related to other indicators of the standard of living, height is not considered an appropriate proxy due to genetic conditions. There are many random aspects affecting this variable and some controllable but costly variables. Clearly, height in children is an indicator that 
can be compared to a threshold for having a picture of differences between quality of life conditions, but it always includes some components from the parents. As a result, we think that the BMI is a different way to approach it because it includes both weight and height.

Ford et al (2000) found that people with extreme values of BMI have an impaired quality of life, and specifically they found a high risk of being unhealthy in people with the lowest scores of BMI. They use variables related to activity limitation, and mental and physical health to evaluate the standard of living. The negative association between overweight and obesity and Health-Related Quality of Life (HRQL)is corroborated for males and females from all the age groups and ethnicities.

We can distinguish three subsets of individuals according to their BMI score: people with normal, low, and highlevels of BMI. People in the normal range are expected to have their BMI between 18,5 and 25. Individuals with a BMI under 18.5, have Chronic Energy Deficiency (CED), which is more common in low income countries (Nubéet al, 1998). These individuals are underweight and in some cases suffer from severe thinness (BMIless than $16) .^{3}$

People with BMI-scores higher than 25 are not related to high standard of living because they are predisposedto heart attacks, some types of cancer, diabetes, and other physical limitations. Obese and overweighed people have different problems when compared to thin people, for example in terms of mobility, self-esteem, or the reasons (including the socioeconomic ones) for being out of the normal BMI range.

Nevertheless, there can be differences within the groups (underweighted and overweighed). Kolotkinet al (2002)analyze the impact of overweight on the standard of living using variables like physical function, sexual life, and public distress, among others, and they conclude that there are important differences in the standard of living among obese people. They find that the HRQL of people with high scores of BMI is statistically and significantly different. The worst HRQL is for the group of people enrolled in treatments for losing weight, but even for the latter, HRQL varies depending on the methods people use for losing weight (gastric bypass, clinical trials...).

3 Energy deficiency is associated with a higher vulnerability to illness, lower productivity, increased mortality, and it has special negative effects on pregnant women since it enhances the risk of low birth weight with the respective intergenerational health and malnourished problems (Shaheen and Lindholm, 2006). 
In short, obesity is almost as undesirable as CED; although being either above or under certain range of BMI could be considered undesirable in terms of quality of life, the dimension in the standard of living is different.

Considering that the standard of living is the same for people being in opposite sides of the scale of BMI range (very thin or very fat), could be as questionable as considering that people in the same range of the BMI have the same standard of living. However, for the purpose of this paper the conditions that explain an extremely low or high BMI, although different, are considered in both cases undesirable for the individuals. Waaler (1984) finds that in the case of Norway, men who have a BMI under 22 or above 28 , have higher death rates. Other studies also confirm the negative association between obesity and quality of life (Han et al [1998], Lean et al [1998, 1999], Ford et al [2000]). Therefore, having a BMI out of the normal range could be linked to a lower standard of living and it is a public health concern since it brings some intergenerational effects.

In the case of overweight, Delva et al (2007) affirm that the BMI affects the standard of living and that some lifestyle behavior affects the BMI. For instance, they find evidence that suggest that exercising, consuming fruits and vegetables, and spending less hours watching televisionreduce the risk of overweight(being at or above the $85^{\text {th }}$ percentile of age and gender adjusted BMI). Besides, the effects of television could be stronger for people from low SES and ethnic groups because, in general, they spend more time watching television than people from higher income groups.This illustrates the fact that lifestyle behavior and income have consequences on health variables such as the BMI and hence on the standard of living. In general, socioeconomic status andhealthdisorders may be correlated; in the case of obesity, Sobal (1989) and Delvaet al (2007) find a negative correlation between overweight and socioeconomic status.

\section{Socio economic status, the BMI, and other anthropometric measures}

Fernald (2007) explores the relationship between the BMI, SES, and beverage consumption amongrural (low-income) Mexican population. For both male and female, she finds a positive relationship between the BMI and educational level, occupation, housing conditions, household assets, and self- 
reported social status. The positive correlation between the BMI and family income only has significance in the case of women. However, after analysing this variable in a more complete model, Fernald (2007) concluded that it is not significant for either sex. The BMI is also positively correlated with alcoholic beverage consumption(which are associated with an upper SES) for both men and women. She proposes that this result could explain the positive relationship between obesity and SES for the case of the low-income population studied. Sobal and Stunkard (1989) find a negative relationship between obesity or overweight and socioeconomic status for women in developed countries, but the relation seems to be inexistent in the case of children and men. For developing countries the relation is positive for both men and women.

The relationship between SES and weight disorders could also be analyzed by using the literature that attempts to explain the correlation between health and education (the SES indicator). This relation could be interpreted in different ways. On the one hand, a better education allows people to be healthier, but at the same timea better health can improve school performance. On the other hand, Mac Innis (2006) proposes that variables such as genetics could affect both health and education in the same direction. He concludes that college completion reduces the probability of overweight and other disordersin the case of Vietnam. According to Mac Innis (2006) the impact of college education on health (smoking, obesity, among others) can operate through the relation with productivity (healthier people are more productive) and income (wealthier people can afford a better protection).

Besides weight, we can study the relationship between socioeconomic variables and stature. Nevertheless, at the individual level, the height-income relation may not be linear because although poverty is importantly related to malnutrition (and the respective consequences on stature), the fact of having been brought up in a wealthier family does not ensure the possibility of being a "giant"(Steckel, 1985). When we are interested in height as an indicator of the standard of living and its relationship with per capita income, variables like income or wealth distribution and diet or nutritional requirements should be included in the analysis (Steckel, 1985).

For the Colombian case, Meisel and Vega (2007)analyze the evolution of height between 1910 and 1984 and found outan improvement in the biological standard of living, which is one of the aspects of quality of life as a 
whole.The authors find that stature has significantly increased for both men and women, for all socioeconomic status in all Colombian regions. Additionally, they find-convergence that allows to state that regions with less stature at the beginning of the period were those which reported the highest growth rates. ${ }^{4}$ In other words, running separate regressions for men and women between the logarithm of the average height in 1910 and the rate of growth between 1910 y 1985 reveal a negative relationship.

This increase in height of Colombians could be explained because of the better performance in health, nutrition, and labour conditions. They conclude that the quality of life has increased in this period and it has also become more equitable, as a result of the reduction in dispersion as a consequence of the convergence.

\section{Data and the Model}

In this study we use the Body Mass Index, (weight in kilograms over the squared height in meters, WHO; 1995), -BMI hereafter-, as a proxy of the Standard of Living. The Demography and Health Survey(DHS) is carried out everyfive years by Profamilia, -a Colombian institution aimed to guide contraceptive behavior in the population-, and itincludes information about socioeconomic conditions and anthropometry of the population. The survey is representative for the whole country and for the regional level as well, including zone of residence. For Colombia, the DHS is the only data base available with information about anthropometric measures for more than 100.000 people; besides, it captures other socioeconomic variables that make it the best tool to conduct research in economics of health. But the information about anthropometric measures is not longer asked to the people.

In order to clean the data for avoiding biased conclusions, we exclude people under 15 years old because the anthropometric measures such as height and weight could depend on the stage of growth in their childhood or adolescence. We alsoexclude observations with the BMI scores out of the interval[13, 50] (more than 70 cases) that could be considered either outliers or information containing mistakes (for instance, errors at the moment of the interview) and we take out of the sample pregnant women and people whose information about education is not available. After these exclusions, we rest with 72.239 observations.

4 In Economic Growth -convergence refers to the fact that poor economies have higher growth rates than richer ones which reduces the variance of the Gross Domestic Product among countries. 
First of all, it is important to note that about $40 \%$ of the population is above the normal range in the BMI with a higher incidence on women (see Table 1). Proportionally, there are more females with higher scores in BMI than men, and we found that about 50 percent of the people are out of the normal range (Table 1).The differences in BMI across groups of population are not statistically significant though can be relevant and worth to mention. Average BMI is slightly higher for urban areas, for the capital city, for the less educated, for the poorest, for people who self-report the worst health status, for people out of the health system, for women and the BMI increases with the age (Table2 and 3 ).

Table 1. Distribution of BMI in Colombia 2005

\begin{tabular}{lcccc}
\hline & BMI & Female & Male & Total \\
\hline Severe Thinness & $<16$ & 0,38 & 0,49 & 0,42 \\
Moderate Thinness & $16-17$ & 0,85 & 1,20 & 0,98 \\
Underweight & $17-18,5$ & 3,68 & 4,95 & 4,16 \\
Normal & $18,5-25$ & 48,87 & 57,71 & 52,24 \\
Overweight & $25-30$ & 31,05 & 27,78 & 29,80 \\
ObeseLevel-I & $31-35$ & 14,30 & 7,72 & 11,79 \\
ObeseLevel-II & $36-40$ & 0,86 & 0,16 & 0,59 \\
\hline Total & & $38 \%$ & $62 \%$ & 100 \\
\hline
\end{tabular}

Source:DHS-2005.

In the final sample used in the estimations, $75 \%$ of the observations come from urban areas, $62 \%$ are women, and almost $6 \%$ are from Bogotá, Colombia's capital city. The fact of having an important gender incidence in the survey comes from their focus on demographic and fertility trends. As it can be seen, higher BMIs are more frequent in women. 
Table 2. Descriptive statistics for the BMI

\begin{tabular}{llcccccc}
\hline Group & Category & Mean & Std.Dev & Mín & Max & P25 & P75 \\
\hline \multirow{2}{*}{$\begin{array}{c}\text { Area of } \\
\text { residence }\end{array}$} & Rural & 24,9 & 4,2 & 18,5 & 50,0 & 22,0 & 27,4 \\
& Urban & 24,4 & 4,5 & 18,5 & 49,8 & 22,5 & 28,4 \\
\hline \multirow{5}{*}{ Region } & Atlantic & 25,3 & 4,5 & 18,5 & 50,0 & 21,9 & 27,9 \\
& Eastern & 25,7 & 4,3 & 18,5 & 49,3 & 22,5 & 28,1 \\
& Central & 25,5 & 4,3 & 18,5 & 49,7 & 22,3 & 28,1 \\
& Pacific & 25,8 & 4,5 & 18,5 & 49,7 & 22,5 & 28,3 \\
& Bogotá & 25,7 & 4,3 & 18,5 & 48,8 & 22,5 & 28,0 \\
& National & 26,3 & 4,5 & 18,5 & 49,8 & 23,0 & 28,9 \\
\hline
\end{tabular}

Source: DHS, 2005

In the case of the variables used to obtain the BMI, neither weight nor stature hasa normal distribution (Fig. 1 and Table2). This can be explained because of the different factors (genetics, nutrition, physical activity or exercise) that can affect these variables in different directions (enhancing or reducing weight) depending, for instance, on age. After certain age, the index only changes due to one of the two variables as it can be note with the BMI average per age-range. Nevertheless, in the case of the height distribution, mean and median coincide. The information suggests that men are taller than women and are expected to have higher weight, on average. For the Colombian case there is previous evidence consistent with the fact that men tend to be taller than women. For the period 1905-1985 Meisel and Vega (2007) find that on average men are 11 centimeters taller thanwomen. 
Table 3. Sample Characteristics of Weight (Kgms) and Height (M.)

\begin{tabular}{lccccccccc}
\hline & \multicolumn{3}{c}{ Women } & \multicolumn{3}{c}{ Men } & & Total & \\
\hline \multirow{3}{*}{ Mean } & BMI & Height & Weight & BMI & Height & Weight & BMI & Height & Weight \\
StdarDev & 25,19 & 1,55 & 60,37 & 23,89 & 1,67 & 67,00 & 24,70 & 1,60 & 62,90 \\
Median & 4,84 & 0,06 & 11,92 & 4,12 & 0,07 & 12,86 & 4,63 & 0,09 & 12,70 \\
Skewness & 24,54 & 1,55 & 58,80 & 23,35 & 1,67 & 65,40 & 24,08 & 1,59 & 61,30 \\
kurtosis & 0,84 & $-0,04$ & 0,85 & 0,75 & $-0,23$ & 0,71 & 0,86 & 0,22 & 0,78 \\
& 4,09 & 3,65 & 4,30 & 4,01 & 4,75 & 4,03 & 4,23 & 2,94 & 4,07 \\
\hline
\end{tabular}

Source: DHS 2005, Colombia.

Figure 1.

Distribution of Weight

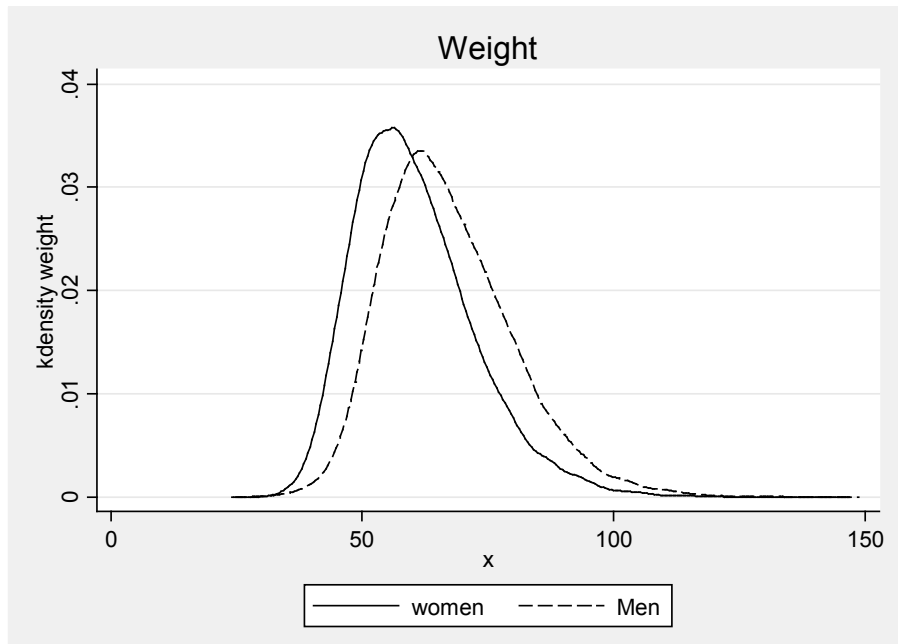

Source: DHS 2005, Colombia.

Revista Econômica, Niterói, v 13, n 2, p. 77-99, dezembro 2011 
We also find that the mean of the BMI in Colombia is in the normal range (24.75), although is located near the upper limit of this range. However, there is a statistical difference between women and men's BMI. Besides, the standard deviation of this indicator suggests that there is more homogeneity in the group of men, in which the standard deviation is lower than in the group of women. The distribution of this variable also indicates that it does not follow a normal distribution (Figure 2).

Figure 2.

Distribution of BMI

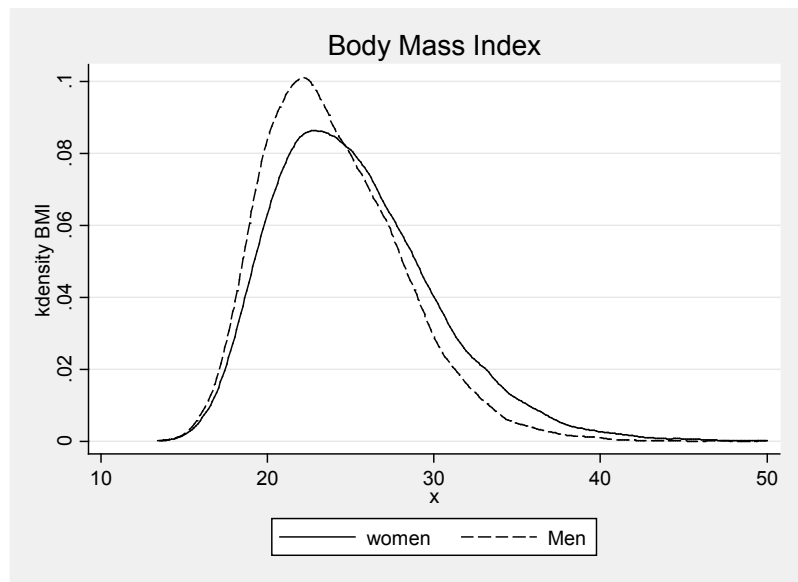

Source: DHS 2005, Colombia.

By regions of residence, it does not seem to be important differences in the BMI distribution, although in the case of Bogotá the population is more homogeneous and we find less people in the extreme cases of BMI categories. People from urban areas have, on average, a slightly higher BMI score (24.94) than people from rural areas (24.28). This situation may be a consequence of factors such as job and nutrition, which are very specific in each area. Rural inhabitants in Colombia normally have jobs that are intensive in physical effort and they usually have a diet rich in carbohydrates; the opposite is true in the case of people who live in urban areas, though there are disparities across income groups.

Even if people are in the extreme categories of BMI, they may consider themselves as healthy (Figure 3). Meanwhile, 75 percent of people who state having an excellent or good health have a BMI of 27 or less and in the case of people who 
report being unhealthy, this value is 28 . It is also found thatthe group of people who feel healthy is more homogeneous (standard deviation of BMI is 4.5) than the group of people who state they are not very healthy (standard deviation is 5). We can conclude that there is a direct relationship between self reported health status and BMI.

Figure 3.

BMI and Self-reported health status

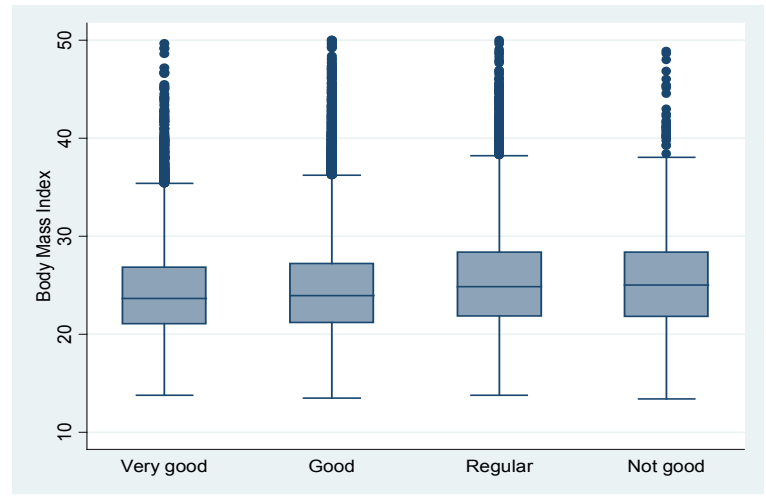

Source: DHS 2005, Colombia.

We made two distinct approaches for the model. One of them is normative because it takes into account the standardized BMI ranges for sorting the population, meanwhile the other is relative to the actual distribution of the people. In the former, we define our categorical variable $\boldsymbol{y}_{1}$ as follows:

$$
y_{1}= \begin{cases}0 & \text { if } 18.5<B M I<25 \\ 1 & \text { if } B M I \in(17,18.5) \text { or }(25,30 ; \\ 2 & \text { if } B M I \in(16,17) \text { or }(30,39) \\ 3 & \text { if } B M I<16 \text { or } B M I>39\end{cases}
$$

Under this specification, people who are under or above the normal range are equally codified, but it includes more categories for taking into account how far from normal range they are.The variable gathers different ranges of the BMI; for instance, when it takes the value of 2 it includes people in the moderate thinness category and also in the obese-Igroup. It could be discussed that the conditions for people under the normal range and the conditions for those above the normal rage are very different in terms of poverty. People in the lower group of weight distribution could be characterized by not having access to food or preventive health. Meanwhile, 
those in the upper groups probably do not have barriers to access to food. The problem is that we want to go beyond the access and include other aspects such as the quality of access. The availability of food does not guarantee good health. In the specific case of Colombia,the food-composition commonly used in low income households in urban as well as in rural areas is characterized by high incidence of carbohydrates and low consumption of vegetables, fruits and proteins. ${ }^{5}$ This condition increases the weight on average but it is also associated to health problems. The second specification of the dependent variable is related to the distribution of people around the index. In this sense, our interest is to assess the differences with the mean in the population. The main intuition behind this is the effect of peers on own dietary behavior. In many societies, the individuals' choices in things such as food, clothing and hobbies are highly influenced by the social network where the people live. Formally, the variable $\mathrm{y}_{2}$ is defined:

$$
v_{2}=\left\{\begin{array}{l}
0 \text { if } \mathrm{BMI} \in(\mathrm{BMI}-\sigma, \mathrm{BM}+\sigma) \\
1 \text { if } \mathrm{BMI} \in(\mathrm{BMI}-2 \sigma, \mathrm{BM}-\sigma) \cup(\mathrm{BMI}+\sigma, \mathrm{BM}+2 \sigma) \\
2 \text { if } \mathrm{BMI} \in(\mathrm{BMI}-3 \sigma, \mathrm{BMI}-2 \sigma) \cup\left(\mathrm{BMI}+2 \sigma, \mathrm{BMI}+3 \sigma_{*},\right.
\end{array}\right.
$$

Where, $\boldsymbol{B} \overline{\boldsymbol{M}} \boldsymbol{I}$ is the mean of the $B M I$ and $\sigma$ is the standard deviation of the sample. Then our $\mathrm{y}_{1}$ variable represents a normative measure and $\mathrm{y}_{2}$ is a relative measure. -

The empirical strategy starts from the estimation of a probabilistic model, where there are more than twice categories in the dependent variables and the order has meaning itself. Then, we use a Ordered Probit as follows:

\section{$\operatorname{Pr} o b(Y i)=\beta_{0}+\beta_{i}$ gender $+\beta_{2} a g e+\beta_{j} a g e^{2}+\beta_{4} L C I+\beta_{5} L C I^{2}+\beta_{6}$ Urban $+\beta_{7} X+e$}

The set of explanatory variables includes, age, gender, region of the country, area of residence (urban or rural), and socioeconomic variables (education level, or LCI). It also includes a vector of variables related to health conditions (self reported health-status, recent medical consultation, whether the person has a physical disability and another dummy for the insurance condition). The inclusion of the zone where individuals live (urban or rural) is a consequence of the particular differences in the type of work and food among both areas, which may influence the BMI and hence, the standard of living. Among the variables related to health status, we include the difficulties for walking, since it is reasonable to think that a person with such disabilities might exercise less and consequently might also have a higher BMI, associated to an impaired quality of life (Table 4).

5 The relative cost of these food with respect to other in high. 
Table 4.

Explanatory Variables

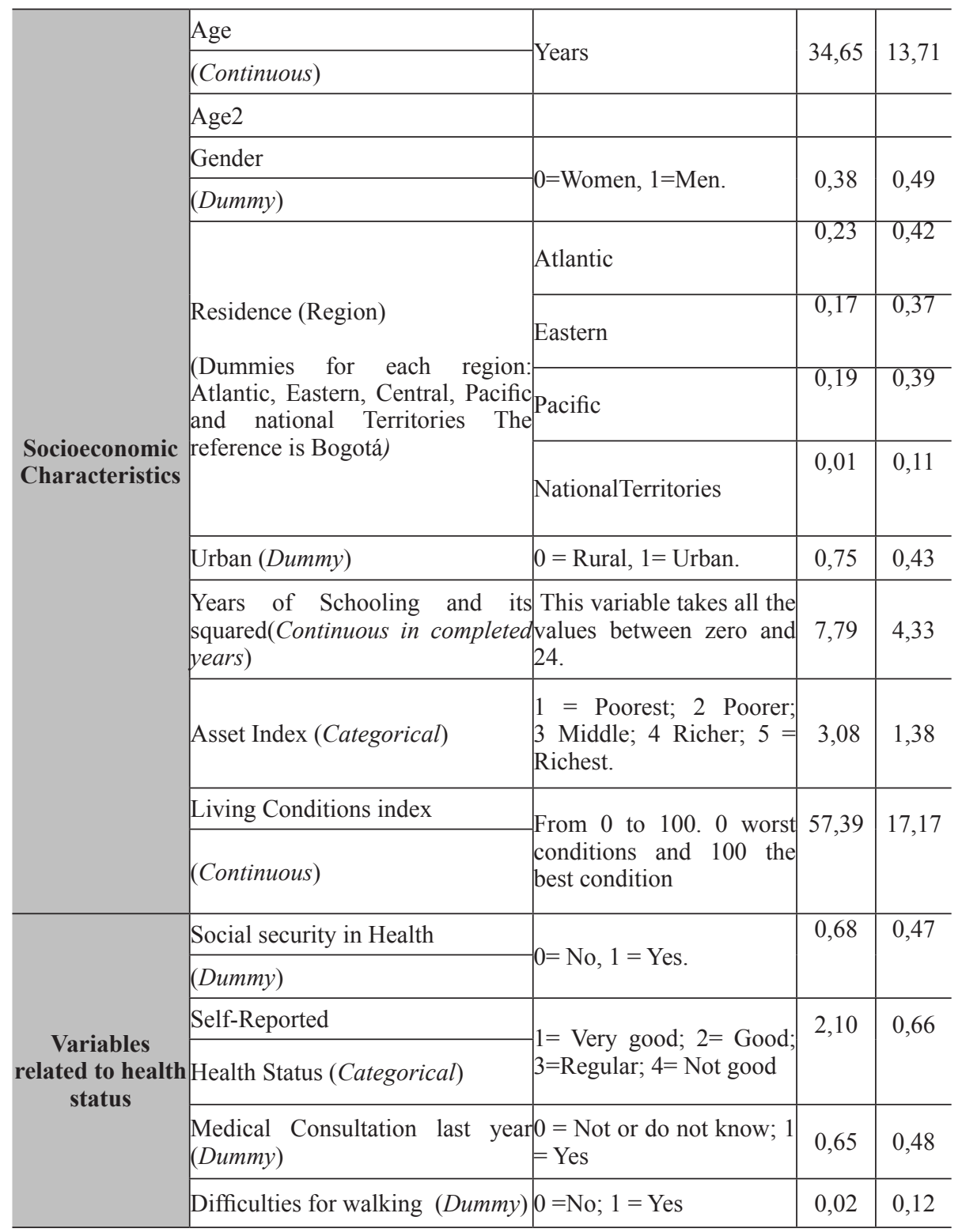

Revista Econômica, Niterói, v 13, n 2, p.77-99, dezembro 2011 
The LCI is an indicator estimated by principal components, which includes information about several household characteristics in one index ranging from 0 to 100 . The set of variables included in the construction of LCI are similar to the ones included in the index used in Colombia for targeting social assistance (SISBEN, in Spanish). These are wall and floor materials, parental educational achievement, children school attendance and overcrowding (according to the number of people living per roomat home). Although it is includes assets, but it may give more information about the standard of living of families because of the inclusion of human and physical capital stock. ${ }^{6}$

It is important to note that we are estimating a non-linear relationship in our specification, but at the same time, we also include non-linear variables in order to test whether the relationship is stable under each group and whether the marginal effects are constant. They are age, schooling and living conditions index.

Table 5 summarizes the distribution of the dependent variables that will be used in the models estimated. In both specifications, zero is considered as the normal or reference category reflecting a better standard of living. Although almost all the people are concentrated in the group that has a better quality of life, there are individuals located in the worst extremes.

Table 5. Distribution of Dependent Variables

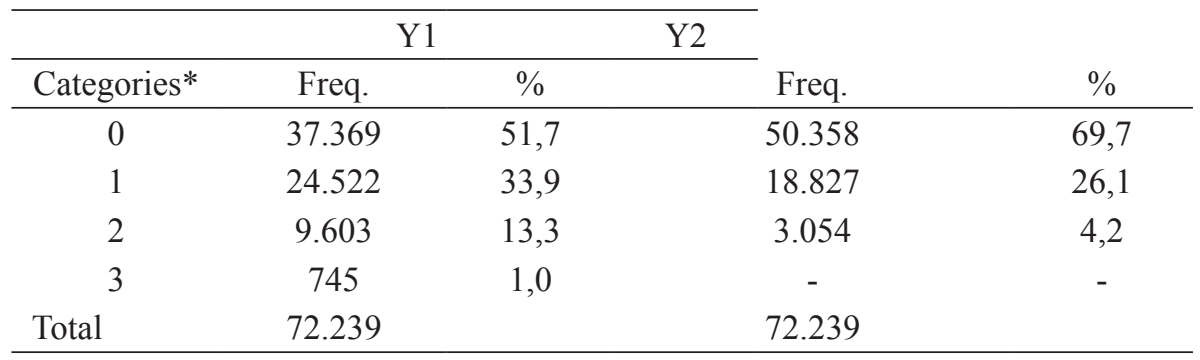

* Values that take a variable in the same category have different meanings.

We run two models (depending on the use of the education or LCI variable) for each dependent variable (y1, y2). Since ordered probit coefficients cannot be read in the same way as ordinary least squares (OLS),

$6 \quad$ The program used is available upon request. 
we only show the marginal effects. ${ }^{7}$ Results show that, in general, marginal effects of the ordered probit estimation using $Y_{1}$ (Table 6) and $Y_{2}$ (Table 7) are analytically the same when we use LCI or education as a proxy of socioeconomic conditions. ${ }^{8}$

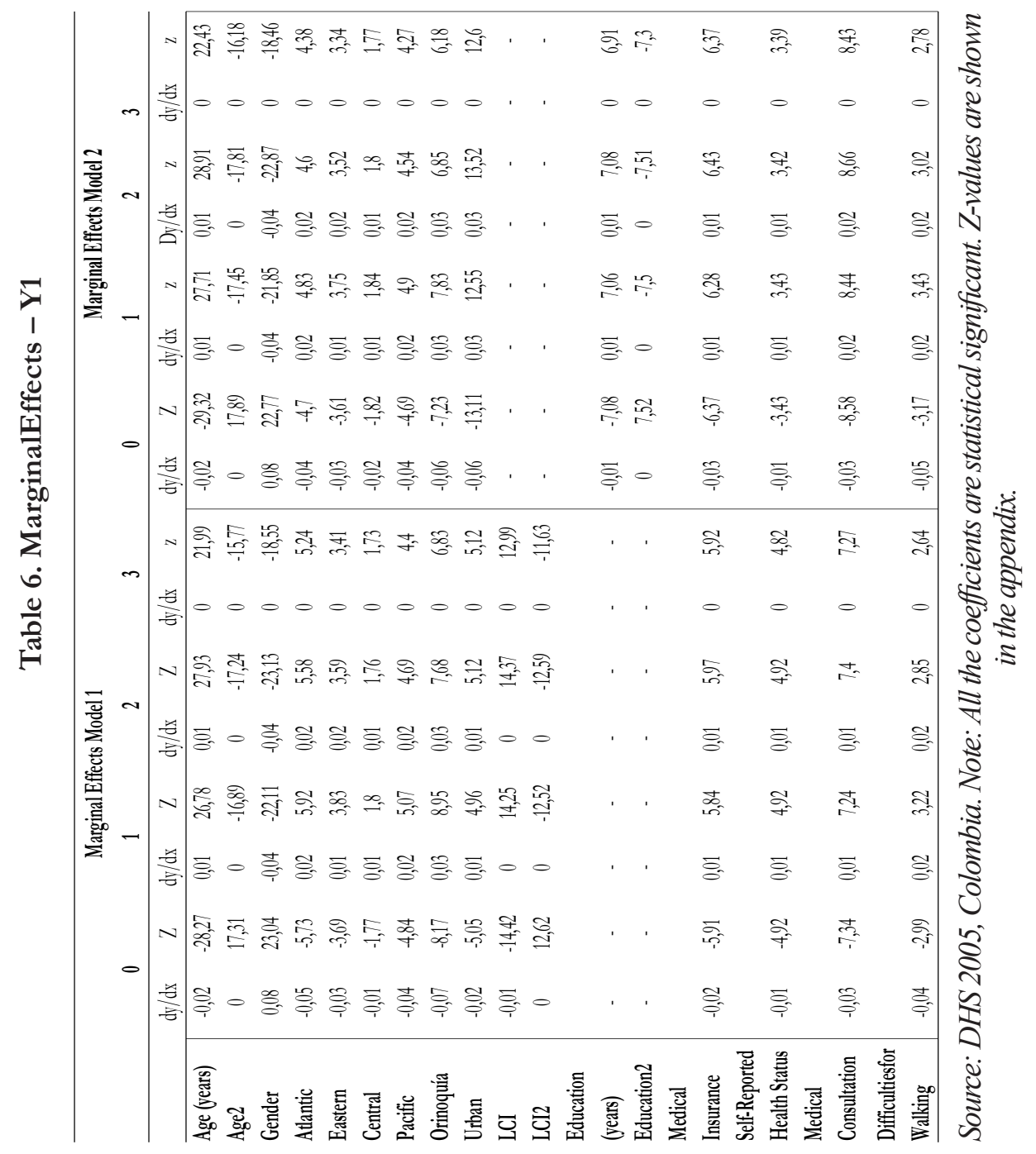

$7 \quad$ For more details about Ordered Probit Models see Wooldridge (2002).

8 Marginal effects obtained using Stata 11.0, are estimated at their mean values. In the case of dummy variables such as gender, this estimation is done on the mean, which is the percentage of people with the value 1 in the definition of the dummy.

Revista Econômica, Niterói, v 13, n 2, p. 77-99, dezembro 2011 
94 - An alternative measure of Standard of Living: The Body Mass Index in Colombia

Table 7. Marginal Effects - Y2

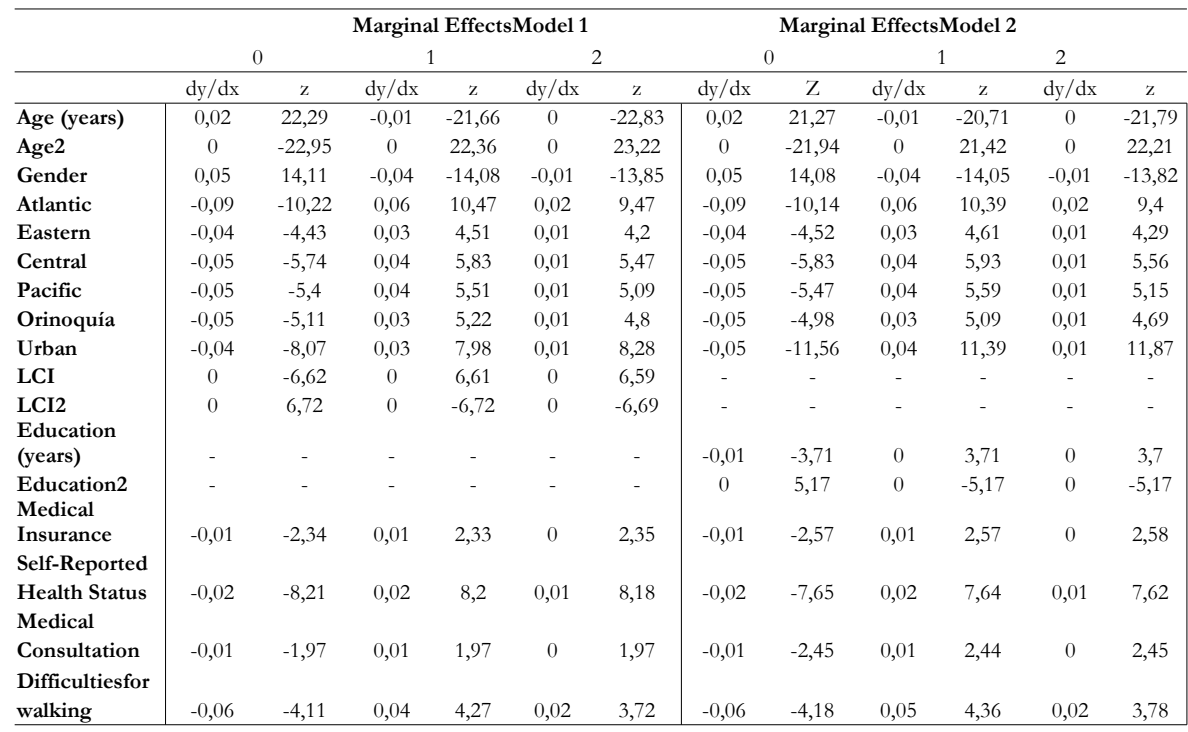

Source: DHS 2005, Colombia.

Marginal effects indicate that being man or living either in Bogotáor in rural areas enhances the probability of being in the range of normal standard of living $(\mathrm{y}=0)$ and reduces the probability of being out of it. In other words, the fact of being a woman or living out of Bogotá increases the probability of having weight problems (either overweight or low weight). This result also shows that gender differences are along the same lines thanin other previous findings.It is interesting to point out that people from rural areas tend to exercise more (at work and to go there) than urban inhabitants, who have access to more transportation facilities, but at the same time, the availability of variety of food is limited in many rural areas of the country.

The result related to Bogotá is consistent with the findings that show that in this city, people with a BMI higher than that of $75 \%$ of population report a score that is lower than the same percentile in other regions. It could be a consequence of having more places for practicing sports, such as gyms, parks, among others, compared to other cities.

There are non-linear and significant relationships between the BMI and the living conditions; the same is found for the relationship between BMI and 
the years of education completed.This finding is important for health policy, but the sign and the size of the coefficients show that there is a small impact on the probability of being in any category. We test other specifications and the results are similar. Increases in age reduce the probability of being in a normal range, which requires attention by preventive programs and in the diffusion of good nutritional habitsstarting fromearly childhood and adolescence.

Besides these two specifications, the socioeconomic variable is approached by using an asset index -that ignores a more complete approach to the standard of living- or socioeconomic strata instead, and the main results were the same. In all the cases we include the educational achievement of the household head or his/her BMI and the main conclusions do not change.

According to the variables associated to health status, marginal effects show that people who consider themselves healthy, individuals who have not had recent medical consultation, or people without problems for walking, have less probability of being out of the normal range of BMI. These results are robust to both specifications of the model.

For the $\mathrm{Y}_{2}$ case, conclusions are very similar to those found earlier. According to the definition of the dependent variable, the standard of living decreases with higher values of Y2. The results indicate that the fact of being a man, living in Bogotá or in rural areas, increase the probability of being healthier.

In both models -either the one that includes education or LCI- coefficients of marginal effects have the same sign; besides, signs of the categories 1 and 2 are always opposite to the sign of the category 0 . In the case of the variables that approach to socioeconomic conditions, the results show that both LCI and years of education have small coefficients that always have statistical significance and indicate that the effect of these variables is nonlinear.

In order to test the robustness and the predictive level of these models, we estimated the mean probabilities and the out of the sample forecast probabilities. Table 8 shows the values that take the dependent variable (in rows) and the average of the predicted values for all the observations in the correspondent category (in columns). For example, it means thaton average, for the observations in the zero category of the first model (Y1)the model predicts a probability of $56 \%$ for being in that category, and probabilities of $32.1 \%, 11.1 \%$ and $0.8 \%$ for being in the first, second, and third categories. 
As it can be seen, there could be an important relationship between the mean probabilities reported and the distribution of the frequencies of the variables (see Table 5). In each specification the highest mean probability corresponds to the predicted value for the category zero. It means that even for the group of observations that takes values different from zero (in either specification), the model leans to predict that those observations would be in category 0 .

Table 8. Mean Probabilities

\begin{tabular}{|c|c|c|c|c|c|c|}
\hline & & & P0 & P1 & $\mathbf{P 2}$ & P3 \\
\hline \multirow{8}{*}{ Y1 } & \multirow{4}{*}{ Model 1} & 0 & 0,56 & 0,32 & 0,11 & 0,01 \\
\hline & & 1 & 0,49 & 0,36 & 0,15 & 0,01 \\
\hline & & 2 & 0,44 & 0,38 & 0,17 & 0,02 \\
\hline & & 3 & 0,50 & 0,34 & 0,15 & 0,01 \\
\hline & \multirow{4}{*}{ Model 2} & 0 & 0,56 & 0,32 & 0,11 & 0,01 \\
\hline & & 1 & 0,49 & 0,36 & 0,15 & 0,01 \\
\hline & & 2 & 0,44 & 0,37 & 0,17 & 0,02 \\
\hline & & 3 & 0,50 & 0,34 & 0,15 & 0,01 \\
\hline \multirow{6}{*}{ Y2 } & \multirow{3}{*}{ Model 1} & 0 & 0,70 & 0,26 & 0,04 & - \\
\hline & & 1 & 0,69 & 0,27 & 0,05 & - \\
\hline & & 2 & 0,68 & 0,27 & 0,05 & - \\
\hline & \multirow{3}{*}{ Model 2} & 0 & 0,70 & 0,26 & 0,04 & - \\
\hline & & 1 & 0,69 & 0,27 & 0,05 & - \\
\hline & & 2 & 0,68 & 0,27 & 0,05 & - \\
\hline
\end{tabular}

\section{Conclusions}

The exercise proposed in this document sheds some light on the relationship between BMI and standard of living in Colombia. First, socioeconomic status is a significant determinant of quality of life when the standard of living is proxied by the BMI. The evidence presented confirms that there are nonlinear relationships between age, socioeconomic status and the variable that approaches the quality of life (BMI).This implies that public policy should be targeted on those groups who require fewer investments for having higher increases in the standard of living. The estimations of the different models show that results are robust to neither of the socioeconomic variables used. 
Second, assuming that scores of BMI extremely high or low do not reflect ideal conditions of life, estimations confirm that the fact of living in Bogotá, or in rural areas or being a man, is associated with a better standard of living (i.e. there is a higher probability for the population, to be in a normal range of quality of life). In the case of women, the association with low weight could be explained because of the social pressures that may affect this particular population. However, our estimations reveal that on average women have higher values of BMI.

In this sense, at least in the short run, a health policy that seeks the improvement of BMI among people should be focused on women. This population is especially important since BMI problems in pregnant women can have intergenerational consequences and many of them cannot return to their pre-pregnancy weight. Besides, health policy ought to take account of the differences in nutrition habits between rural and urban areas (and therefore, between rural and urban women), which may be the cause of the fact that people living in urban areas have a higher probability of being in anupper range of BMI, and hence, of having an impaired quality of life, compared to individuals in rural areas. In order to achieve an improvement in the standard of livingby means of an advance in BMI indicators, health policy makers would need to encourage healthier nutrition and exercise habits among the population.

One important aspect for health policy is the direct relationship between BMI and age. This is one task for policy makers because increases in IMC are strongly related to heart attacks and other health problems. Taking into account the costs generated by health problems associated with weight -even in developed countries-, and the deaths caused by such motives, it is important to give a centralrole in health policy to programs focused on forming adequate nutrition exercise habits among children. 
98 - An alternative measure of Standard of Living: The Body Mass Index in Colombia

\section{References}

DELVA, J., Johnston, L y O'Malley, P. (2007). The Epidemiology of overweight and Related Lifestyle behaviors, Ratial/Ethnic and Socioeconomic Status Differences Among American Youth. American Journal of Preventive Medicine, 33, 178-186.

FERNALD, Lia, (2007). Socio-economic status and body mass index in low-income Mexican Adults.Social Science \& Medicine 64. p. 2030-2042

FOGEL, R. (1989). Nutrition and the Decline in Mortality Since 1700: Some Preliminary

Fndings, in "Long-Term Factors in American Economic Growth", 439-555.

FORD, E., Moriarty, D., Zack, M., Mokdad, A. and Chapman, D. (2000).Self-reported Body

Mass Index and Health-Related Quality of Life: findings from the Behavioral Risk Factor Surveillance System. Obesity Research, 9, 21-31.

GAMBOA, Luis F. José Guerra. (2006). Una Evaluación Estática y Dinámica de los Cambios en Calidad de vida en Colombia durante 1997-2003. Revista de Economía del Rosario Vol. 9. No. 2. Diciembre p. 125 - 159.

GRAHAM, C., Pettinato, S. (2000).Happiness, markets\&democracy: LatinAmerica in corporativeperspectives. Working Paper.13, p.1-29.www.frontlineonline.com

HAN, T., Tijhuis, M., Lean, M. and Seidell, J. (1998). Quality of life in relation to overweight and body fat distribution. American Journal Public Health, 88, 1814-1820.

KOLOTKIN, R., Crosby, R. and Williams, R. (2002).Health-Related Quality of Life Varies among Obese Subgroups. Obesity Research, 10, 748-756.

KOMLOS JOHN, MarekBrabec.(2010) The Trend of BMI Values among US Adults. CESIFO WORKING PAPER NO.2987 March.

LEAN, M., Han, T. and Seidell, J. (1999). Impairment of health and quality of life using new US Federal guidelines for the identification of obesity.Arch Inter Med, 159, 837-843.

MEISEL, A. and Vega, M. (2006).Los orígenes de la antropometría histórica y su estado actual. Cuadernos de historia económica y empresarial, Banco de la República (Cartagena). MEISEL, A. and Vega, M. (2007).La estatura de los colombianos. Antropometría histórica, 1870-2003. Centro de Estudios Económicos Regionales (CEER) Cartagena. Colección de Economía Regional. Banco de la República, Colombia.

NUBÉ, M., Asenso-Okyere, W. and Van den Boom, G. (1998) Body Mass Index as indicadorof standard of living in developing countries. European Journal of Clinical nutrition, 52, 136-144. SENAMARTYA., (1987). The Standard of Living: Lecture I, Concepts and Critics, en Hawthorn Geoffrey., ed. The Standard of Living, CambridgeUniversity Press,

SENAMARTYA., (1987b). The Standard of Living: Lecture II, Lives and Capabilities, en Hawthorn Geoffrey., ed. The Standard of Living, CambridgeUniversity Press, 
SHAHEEN, R. y Lindholm, L.Quality of life among pregnant women with chronic energy deficiency in rural Bangladesh. Health Policy, Volume 78, Issue 2-3, 128-134.

SLOTTJE, D. (1991). Measuring the quality of life across countries. Review of Economics and Statistics 73(4), 684-693.

SOBAL J., A. Stunkard (1989). Socioeconomic status and obesity: A review of the literature. Psychopharmacology Bulletin, 106, pp. 260-275

STECKEL, R. (198??5). The stature \& the standard of living. Journal of Economic Literature 33(December), 1903-1940.

SUGDEN, R. (1993). Welfare, resourses, and capabilities: a review of inequality reexamined by Amartya Sen. Journal of Economic Literature 31(4), 1947-1962.

WAALER, H. (1984).Height, Weight, and Mortality: The Norwegian Experience". ActaMedicaScandinavica, 679.

WOOLDRIDGE, Jeffrey (2002). Econometric analysis of Cross Section and Panel Data. TheMit Press.

WORLD HEALTH ORGANIZATION, WHO (1995). Physical Status: The Use and Interpretations of Anthropometry. WHO Technical Report Series 854. Geneva.

Recebido para publicação em maio de 2011 Aprovado para publicação em Dezembro de 2011

Revista Econômica, Niterói, v 13, n 2, p. 77-99, dezembro 2011 